\title{
Blood Pressure Parameters Among Smokers and Smokeless Tobacco Users in a Tertiary Level Hospital
}

\author{
Habib N ${ }^{1}$, Rashid $\mathbf{M}^{2}$, Begum USN ${ }^{3}$, Akhter $N^{4}$, Akhter D
}

\begin{abstract}
This cross-sectional study was carried out to assess blood pressure parameters among adult male smokers and smokeless tobacco users. For this purpose, 105 male respondents were selected. They were divided into two groups; Group A-consisting of 30 were smokeless tobacco users and group $B$ consisting of 75 smoker patients The participants were selected from medicine outdoor of Dhaka Medical College Hospital. In this study, the mean ( $\pm S D)$ of systolic blood pressure were $154.50 \pm 26.793 \mathrm{~mm}$ of $\mathrm{Hg}$ in Group A and 151.67 $\pm 19.248 \mathrm{~mm}$ of $\mathrm{Hg}$ in group B respectively. Statistical analysis was done by unpaired ' $t$ ' test, there were no statistical significant differences $(P>0.05)$ of systolic blood pressure between Group A and Group B. The mean $( \pm S D)$ of diastolic blood pressure were

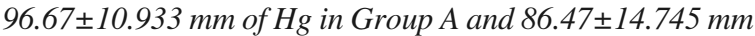
of $\mathrm{Hg}$ in group $\mathrm{B}$ respectively. The mean $( \pm S D)$ of diastolic blood pressure were significantly higher $(P<0.05)$ in Group A than Group B.
\end{abstract}

\section{Introduction}

Blood pressure refers to the pressure inside the arteries. Hypertension means that the blood is exerting more pressure than in normal or healthy. Over time, this weakens and damages blood vessel walls. Hypertension may be caused by thickening of the artery walls, resulting in narrowing and eventual blockage of the vessel. In atherosclerosis, the pressure of pumping blood could 'hose off' debris from damaged artery walls ${ }^{1}$. Smoking has been shown to raise blood pressure by vasoconstriction and accelerated heart rate as acute effect ${ }^{2}$. Different groups have reported that no association existed between smoking habit and blood pressure. One group found that blood pressure of smokers was lower than that of non smokers or that smoking raises blood pressure ${ }^{3}$. The nicotine in cigarettes and the lack of

1) Corresponding Author:

Dr. Nasrin Habib MBBS, Mphil, MPH

Assistant Professor of Physiology

Holy Family Red Cresent Medical College Hospital, Dhaka E-mail Address: drnh77@yahoo.com

2) Dr. Mamunur Rashid MBBS, FCPS Assistant Professor of Medicine Shahabuddin Medical College Hospital, Dhaka

3) Dr. USN Begum MBBS, Mphil Professor of Physiology Holy Family Red Cresent Medical College Hospital, Dhaka

4) Dr. Najneen Akhter MBBS, Mphil Associate Professor of Physiology Holy Family Red Cresent Medical College Hospital, Dhaka

5) Dr. Dilruba Akhter MBBS, Mphil Associate Professor of Physiology Holy Family Red Cresent Medical College Hospital, Dhaka oxygen to the body's tissues causes blood vessels to thin. Smoking makes the body unable to circulate blood properly, which in turn causes high blood pressure. The carbon monoxide from smoking cigarettes causes cholesterol deposits to form on the arterial walls. Blood clots become more likely because of the nicotine ${ }^{4}$. Nicotine raises blood pressure by constricting blood vessels. This occurs because the oxygen in blood decreases and because nicotine directly stimulates the production of a hormone, epinephrine (also known as adrenaline), in the adrenal gland. Epinephrine raises blood pressure by constricting blood vessels ${ }^{5}$.

Every year a man smokes a pack a day, he shortens his life by almost 2 months. Even 1 stick of cigarette can reduce life span of a man about 11 minutes ${ }^{6}$.

Smokeless tobacco use is a significant part of the overall world tobacco problem. Unlike cigarettes and other forms of tobacco, smokeless tobacco is consumed without combustion (without burning). Instead, it is placed in contact with mucous membranes in the mouth or nose, through which nicotine is absorbed into the body. The use of nasal snuff is returning. Different forms of snuff, such as loose or packeted snuff, are used by placing in the mouth. Tobacco may also be prepared in blocks and flakes for chewing. In North America, smokeless tobacco use typically consists of the oral use of snuff (moist or dry). In Central, South and Southeast Asia, smokeless tobacco is usually chewed with another substance, such as ash, lime, cotton, sesame or betel quid (a mixture of nut, lime, and leaves $)^{7}$. Smokeless tobacco is a harmful tobacco product that contains over 3,000 chemicals, 7 including 28 known carcinogens (cancer-causing agents) ${ }^{8}$.

Like cigarettes, smokeless tobacco contains nicotine, and nicotine affects the heart. It is not surprising, then, that studies have found that smokeless tobacco increases heart rate and blood pressure ${ }^{9}$, and puts users at increased risk for stroke, coronary heart disease, peripheral vascular disease (that is, diseases of the arteries and veins) and cardiovascular death ${ }^{10}$. However, it should be noted that some studies have shown no relation between smokeless tobacco use and stroke or cardiovascular mortality ${ }^{11}$. Further rigorous studies are needed to determine more clearly the cardiovascular risks potentially associated with smokeless tobacco use ${ }^{12}$.

So the present study was to find out changes of blood pressure among the smokers and smokeless tobacco users.

\section{Materials and Methods}

The present study was done in the outdoor medicine units of Dhaka Medical College Hospital from January 2011 to 
July 2011. The blood pressure was compared between smokers and smokeless tobacco users. For this purpose, 105 subjects age over 20 years were selected, of whom, 30 were smokeless tobacco users (Group A) and 75 were smokers (Group B) who smoked for more than five years. Smoking history of smokers was recorded on a data collection sheet. All the subjects were explained about the aims and objectives of the study. The test procedures were briefed. Written consent was taken from the person concerned in a prescribed form. A detailed history of each subject including smoking history was obtained by using a pre-tested questionnaire. All data was recorded in data collection form. Statistical analysis of results between the groups was calculated by using unpaired students ' $t$ ' test.

\section{Results}

In this study, among the smokeless tobacco users, the mean $( \pm$ SD) of age was $61.70 \pm 16.379$ years. Mean per day use of smokeless tobacco was $4.8125 \pm 1.64190$ SD. All (100\%) were regular user. The mean $( \pm \mathrm{SD})$ of pulse rate were $84.07 \pm 11.011$ beat $/ \mathrm{min}$. Among the smoker subjects, the mean $( \pm \mathrm{SD})$ of age were $62.61 \pm 15.803$ years. Mean duration of smoking was 13.01 $6.521 \mathrm{SD}$ years. Mean per day smoked was $14.59 \pm 6.870$ SD sticks. All $(100 \%)$ were regular smokers. The mean $( \pm \mathrm{SD})$ of pulse rate were $81.60 \pm 9.868 \mathrm{beat} / \mathrm{min}$.

\section{Systolic blood pressure}

The mean $( \pm \mathrm{SD})$ of systolic blood pressure were $154.50 \pm 26.793 \mathrm{~mm}$ of $\mathrm{Hg}$ in Group A and 151.67 \pm 19.248 $\mathrm{mm}$ of $\mathrm{Hg}$ in group B respectively. There were no statistical significant $(\mathrm{P}>0.05)$ differences of systolic blood pressure in Group A Vs Group B (Table-1).

Table-1: Mean ( \pm SD ) measured values of Systolic Blood Pressure

\begin{tabular}{cccccc}
\hline Group Frequency Percentage & $\begin{array}{c}\text { Systolic blood } \\
\text { pressure } \\
\text { (mm of Hg) }\end{array}$ & P value & Remark \\
\hline A & 30 & $28.57 \%$ & $154.50 \pm 26.793$ & 0.546 & NS \\
B & 75 & $71.43 \%$ & $151.67 \pm 19.248$ & & \\
\hline
\end{tabular}

Group A: Consisted of 30 adult smokeless tobacco users.

Group B: Consisted of 75 adult - smokers.

$\mathrm{NS}=$ Not significant by unpaired " $\mathrm{t}$ " test

\section{Diastolic Blood Pressure}

The mean $( \pm \mathrm{SD})$ of diastolic blood pressure were $96.67 \pm 10.933 \mathrm{~mm}$ of $\mathrm{Hg}$ in Group A and 86.47 $\pm 14.745 \mathrm{~mm}$ of $\mathrm{Hg}$ in Group B respectively.

The mean $( \pm \mathrm{SD})$ of diastolic blood pressure were significantly higher $(\mathrm{P}<0.05)$ in Group A Vs Group B (Figure 1).

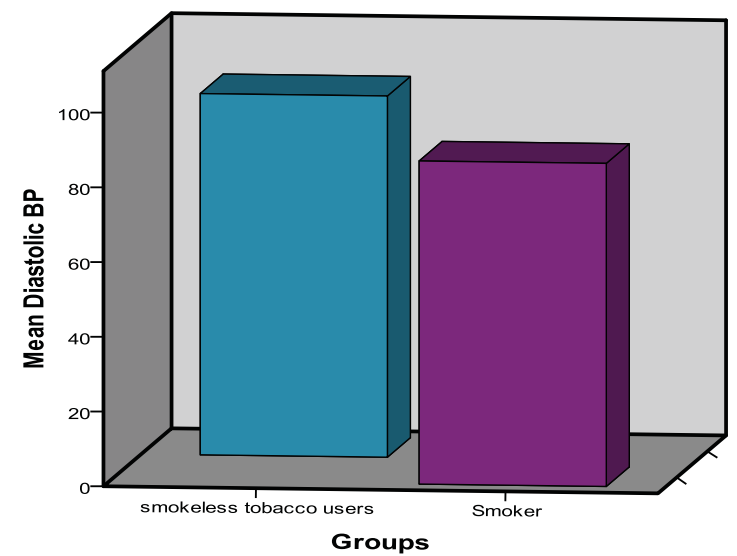

Figure 1: Diastolic Blood Pressure in smokeless tobacco user and smoker

\section{Discussion}

Smoking is harmful for health is well known. Smoking causes death is printed over the cigarette packet as caution note. In Bangladesh, anti smoking law was launched by government in June 2005. In spite of the anti-smoking law, smoking is a common problem in Bangladesh and also a major health problem associated with morbidity and mortality. Smokeless tobacco products are as addictive as cigarettes and can cause the same type of dependence, which makes quitting smokeless tobacco very difficult. Furthermore, nicotine may factor into coronary artery disease, peripheral vascular disease, hypertension, peptic ulcer disease, and fetal effects ${ }^{13}$. The mean $( \pm \mathrm{SD})$ of systolic blood pressure were $154.50 \pm 26.793 \mathrm{~mm}$ of $\mathrm{Hg}$ in Group A (smokeless tobacco users) and $151.67 \pm 19.248 \mathrm{~mm}$ of $\mathrm{Hg}$ in group B (smokers) respectively. The mean $( \pm \mathrm{SD})$ of diastolic blood pressure were $96.67 \pm 10.933 \mathrm{~mm}$ of $\mathrm{Hg}$ in Group A (smokeless tobacco users) and 86.47 $\pm 14.745 \mathrm{~mm}$ of $\mathrm{Hg}$ in group B (smokers) respectively. The mean $( \pm \mathrm{SD})$ of diastolic blood pressure were significantly higher $(\mathrm{P}<0.05)$ in Group A (smokeless tobacco user) than Group $\mathrm{B}$ (smoker).

In this present study, no significant change of systolic blood pressure was associated due to tobacco use between smokeless tobacco users and smokers patient group. Diastolic blood pressure change had a significant association among the smoker and smokeless tobacco users. Other study revealed that current smokers had lower systolic and diastolic blood pressures ${ }^{13}$. In a study, no significant trends for BP varying with number of cigarettes smoked were noted in adults ${ }^{14}$. In another study, diastolic blood pressure decreased with increasing levels of cigarette smoking ${ }^{15}$. A weak relationship was demonstrated between smoking habits and DBP, with the lowest BP in persons smoking greater than 25 cigarettes a day. The relatively small differences in BP may be of pharmacologic or psycho 
behavioral interest, but do not counter the well-described deleterious effects of cigarette smoking ${ }^{14}$. There is generally no association between smoking status and blood pressure ${ }^{15}$.

Smokeless tobacco affects the cardiovascular system and is associated with heart disease, stroke and high blood pressure ${ }^{15}$. One study states that, "Although the evidence is not conclusive, the adverse cardiovascular effects of smokeless tobacco use are less than those caused by smoking but are more than those found in non-users. Other studies also indicate that smokeless tobacco related cardiovascular risks are lower than that of smoked tobacco ${ }^{16}$. One study states that smokeless tobacco use has a positive effect on cardiovascular risk factors in young physically fit men ${ }^{17}$. However, it is important to note that one Indian study from the state of Rajasthan states, there is a significantly greater prevalence of multiple cardiovascular risk factors like obesity, resting tachycardia, hypertension, high total and LDL cholesterol, and low HDL cholesterol, and electrocardiographic changes in tobacco users, chewing or smoking, as compared-to tobacco non-users. Chewing tobacco is associated with similar cardiovascular risk as smoking $^{18}$.

This finding may bear on the possibility that smokeless tobacco in India is produced differently than in Western countries. Due to contrasting results in studies, many conclude that further research should be done on the cardiovascular risks of smokeless tobacco ${ }^{19}$.

\section{Acknowledgement}

All praises are due to the Almighty Allah for enabling me sufficient opportunity and courage and strength to carry out and complete this thesis work.

I would like to express my deepest regards and a profound debt of heart full gratitude to my respected teacher and guide Assistant Professor Dr. Kazi Shafiqul Halim, MBBS, MPH, Department of Epidemiology, NIPSOM, Mohakhali, Dhaka; for his keen supervision, scholastic guidance, constructive criticisms, valuable suggestions, affectionate advice and whole hearted co-operation made this study possible. It would have been difficult on my part to carry out this dissertation without his unfailing and stimulating guidance throughout the study. He deserves more than I can express. I consider myself very fortunate in having him as my guide.

Finally, the sacrifice of my husband Dr. Mamunur Rashid (Shabuj) and loving daughter Faria Rashid (Rim) whom I deprived enormously for the last six months during the course period. Their sacrifices in completion of this study cannot be expressed in words.

\section{References}

1. Better Health Channel, Stroke prevention for high risk groups [Online]. [cited 2008 Aug 7]; Reviewed on: http://www.betterhealth.vic.gov.au:80/bhcv2/bhcarticle s.nsf/pages/ Stroke_prevention_for_high_risk_groups, July 05, 2011.
2. Benowitz NL, Kuyt F. Jacob P. Influence of nicotine on cardiovascular and hormonal effects of acigarette smoking, Clin Pharmacol Ther 1984;36:74-81.

3. Elliott JM, Simpson FO, Cigarettes accelerated hypertension. NZ Med J, 1980;91:447-9.

4. Heart Clinic, Smoking and High Blood Pressure [Online], [cited 2008 Aug 12]; Reviewed on http://www.highbloodpressuremed.com/smoking-andhigh-blood-pressure.html; July 10, 2011.

5. Ilgenli TF, Akpinar O, Acute effects of smoking on right ventricular function. Swiss med wkly 2007; 137:91.

6. Braunwald E, Havser SL, Fauci AS, Longo DL, Kasper DL, Jameson JL, editors. Harrison's principles of internal medicine. 15th ed. New York: McGraw Hill, Health professions division; 2433-5.

7. Kuper, H., Adam, O, \& Buffett, P, Tobacco use, cancer causation and public health impact. Journal of Internal Medicine, 2002;251:455-466.

8. Benowitz, N. L, Pharmacology of smokeless tobacco use: Nicotine addiction and nicotine-related health consequences. In D. R. Shopland (Ed.), Smokeless tobacco or health: An international perspective (Smoking and Tobacco Control Monograph 2, NIH Publication No. 93-3461). Bethesda, MD: National Institutes of Health, U.S. Department of Health and Human Services, 1992.

9. Huhtasaari, F., Lundberg, V., Eliasson, M., Janlert, U., \& Asplund, K, Smokeless tobacco as a possible risk factor for myocardial infarction: A population-based study in middle-aged men. Journal of the American College of Cardiology, 1999;34:1784-1790.

10. Westman, E, Does smokeless tobacco cause hypertension, Southern Medical Journal, 88, 716-720. As cited in Gupta, R., Gurm, H., \& Bartholomew, J. (2004). Smokeless tobacco and cardiovascular risk. Archives of Internal Medicine, 1995;164:1845-1849.

11. Accortt, N. A., Waterbor, J. W., Beall, C., \& Howard, $\mathrm{G}$, Chronic disease mortality in a cohort of smokeless tobacco users. American Journal of Epidemiology, 2002;156:730-737.

12. UK's Action on Smoking \& Health (ASH.) Accessed on July 31, 2007.

13. Frequently Asked Questions. Gothiatek. Accessed on November 25, 2007.

14. Centers for Disease Control and Prevention, "Determination of nicotine, $\mathrm{pH}$, and moisture content of six US commercial moist snuff products - Florida, January-February 1999"; JAMA 281:2279-80.

15. Haddock, C. K., Weg, M. V., DeBon, M., Klesges, R. C., Talcott, G. W., Lando, H., et al., Evidence that smokeless tobacco use is a gateway for smoking initiation in youth adult males. Preventive Medicine, 2001;32:262-267. 
16. Asplund $\mathrm{K}$, "Smokeless tobacco and cardiovascular disease", Prog Cardiovasc Dis, 2003;45:383-94.

17. Siegel D, Benowitz N, Ernster VL, Grady DG, Hauck WW, "Smokeless tobacco, cardiovascular risk factors, and nicotine and cotinine levels in professional baseball players". Am J Public Health, March, 1992;82:417-21.
18. Gupta BK, Kaushik A, Panwar RB, et al., "Cardiovascular risk factors in tobacco-chewers: a controlled study". J Assoc Physicians India, January, 2007;55:27-31.

19. Winn DM, "Epidemiology of cancer and other systemic effects associated with the use of smokeless tobacco". Adv. Dent. Res. September, 1997;11:313-21. 